Supplement

\title{
Full English article from Saratov Journal of Medical Scienific Research (2010-2011 years)
}

Original Text @ Saratov Journal of Medical Scientific Research 2010-2011

Cite as Full English article from Saratov Journal of Medical Scienific Research (2010-2011 years). Russian Open Medical Journal $2012 ; 1: 0106$.

\section{Medical Doctors' Knowledge of Dental Specialty: Implication for Referral}

C.C. Azodo, O. Ehigiator, A.O. Ehizele, O. Ololo

The research goal is to assess Medical Doctors' knowledge of the various dental specialties and to determine if their past dental experience affects their level of knowledge. Resident Doctors and Medical Officers working in the University of Benin Teaching Hospital, Nigeria were surveyed with selfadministered questionnaire in 2008. A total of 142 doctors responded to the questionnaire, giving a response rate of $71 \%$. The female: male ratio was approximately 1:2.5. The designations of respondents were Senior Registrar 21.8\%, Registrar $48.6 \%$ and Medical Officers 29.6\%. The Departments that returned the questionnaire were Internal Medicine 21.1\%, Surgery 19\%, Paediatrics 15.5\% Family Medicine $11.3 \%$, Accident and Emergency 5.6\%, Radiology 4.9\%, Ophthalmology $8.5 \%$, Pathology $5.6 \%$, Anaesthesiology 5.6\% and Mental Health 2.8\% The mean knowledge score was 10.1 \pm 3.3 . (Maximum score $=21$ ). Only a small percentage $(5.6 \%)$ had a good knowledge (scored above 16 ), $79.6 \%$ had a fair knowledge (scored $8-15$ ) and $14.8 \%$ had a very poor knowledge (scored less than 8 ). Doctor with history of previous dental treatment had better knowledge $(P=0.03)$. The knowledge of Medical Doctors about the various areas in Dentistry is presently not satisfactory. Comprehensive care of patients, which includes prompt and appropriate referral, can be optimized by improvement of Doctors' knowledge of dental specialty through seminars and other educational interventions.

Saratov Journal of Medical Scientific Research 2010; 6: 140-143.

URL: http://ssmj.ru/en/2010/1/140

Occupational risk of HIV infection among dental surgeons in Nigerian

C.C. Azodo

Background: Prevention of accidents and management of exposures in the work environment is an important oc $\neg$ cupation health issue. This study objective was to investigate the occupational risk of HIV among Nigerian dental sur-geons. Methods: This descriptive cross sectional survey of 300 dental surgeons practicing in private and government owned dental centers in Nigeria was conducted from June 2006 to January 2007. Results: Percutaneous injury was recorded among $69.3 \%$ of respondents and only $1.2 \%$ had Post exposure prophylaxis. Those with abraded skin that will treat patient without additional barrier were $8.6 \%$. Percutaneous injury was positively related to gender, position, additional qualifications $(p<0.05)$. Conclusion: Percutaneous injury is significantly high and low preventive measure at such exposure. Policies, practices, and trainings geared towards protecting and reducing the prevalence of percu-taneous injury among dental surgeons, and improving post exposure prophylaxis uptake in the event of exposure is a necessity.

Saratov Journal of Medical Scientific Research 2010; 6: 357-360.

URL: http://ssmj.ru/en/2010/2/357

\section{Tegument based in-silico Drug Targeting of Herpes Simplex} Virus-1

Ashish Runthala, Amit Kumar Singh

Alpha Trans Inducing Factor (a-TIF) is a herpes simplex virus type 1 (HSV-1) virion tegument protein present in the tegument layer between the capsid and the envelope, in association with cellular proteins and trans-activated viral activities. a-TIF stimulates the transcription of HSV-1 Immediate Early genes during lytic virus replication. The presence or absence of functional a-TIF protein in vivo is always associated with viral activities. Its role behind latent HSV-1 infection is ambiguous. No drug is designed for HSV till now based on this protein and thus its conformational details can be very important for drug designing purpose. Methods. Docking studies on this protein becomes logical. Four different ligand molecules viz. Adenosine-3'5'-Diphosphate, P1-(5'-Adenosyl) P4-(5'-(2'-Deoxy-Thymidyl)) Tetraphosphate, 9-Hydroxymethylguanine, 9-(4-Hydroxybutyl)-N2Phenylguanine were screened for the study. Results. P1-(5'-Adenosyl) P4(5'-(2'-Deoxy-Thymidyl) Tetraphophate was found to be the best ligand as it showed the lowest docking energy of $-9.238 \mathrm{kcal} / \mathrm{mol}$. Conclusions. The best ligand was found to bind different sites of the a-TIF protein and hence can be utilized to combat HSV-1 successfully, with a synergistic effect of multiplicity of drug molecules on the target protein.

Saratov Journal of Medical Scientific Research 2010; 6: 353-357.

URL: http://ssmj.ru/en/2010/2/353

Preventive Intervention of Pit Fissure Sealant to Reduce New Dental Caries Incidence in the Student of Sumbangsih Primary Schools Jakarta

Risqa Rina Darwita, Iwany Amalliah

The aim of this study to determine whether a pit fissure sealing teeth represents an effective method of decreasing the incidence of new dental caries, to gain the parents, teachers and Sumbangsih Education foundation acceptance on this new activity. Methods. The subjects were 7-11 year of age of 251 student of Sumbangsih Primary School, which located in Kemang, South Jakarta and Grogol, West Jakarta. Intra oral examinations and pit fissure sealing were done in the school dental clinic. The data were analyzed by Chi-square test. The results showed that, the number of student who receives pit-fissure sealant in primary school Kemang was $38 \%$, and Grogol was $62 \%$. The number of tooth with pit fissure sealant in 251 student was 825 tooth, however, the students who were received pitfissure sealant age of 8 and 9 years old (40.36\% and $43.39 \%)$ were higher then the other students of age 7, 10 and 11 years old. After 6 month evaluation, the occlusal sealant retention rates are including to, full complete retention in occlusal molar surface was 383 tooth had full retention higher significant than those of partial loss occlusant sealant retention (174 tooth). Nevertheless, the occlusal with complete sealant loos was significantly lower $(p<0.001)$ than those of full occlusal sealant retention. The new decay was significantly decrease $(p<0001)$ in all student, and almost $100 \%$ of parent of student were accepted the dental 
caries prevention through pit fissure sealant. further, almost more than $50 \%$ of tooth was still having a complete full retention glass-ionomer sealant. Conclusions. These findings were described that pit fissure sealant technique as an intervention for dental caries prevention in Sumbangsih primary school student could prevent the expansion of initial decay.

Saratov Journal of Medical Scientific Research 2010; 6: 386-388.

URL: http://ssmj.ru/en/2010/2/386

Impact of interspousal violence and maternal deprivation on a child's mental health: a case report

Alphonsus N. Onyiriuka

This paper presents a case of an emotionally deprived child with some evidence of child neglect resulting from husband-wife violence and subsequent separation of parents. It also further confirms the long recognized fact that the most successful treatment of growth failure and weight loss due to psychosocial deprivation is restoration of a normal social environment. In particular, it highlights the need for a high index of suspicion and awareness on the part of medical personnel with regard to emotional disorders in children.

Saratov Journal of Medical Scientific Research 2010; 6: 494-497.

URL: http://ssmj.ru/en/node/1745

\section{X-rays referral in an emergency department}

Zohair Jamil Gazzaz, Khalid Obeid Dhafar, Abdul Fatah Sindy, Mian Usman Farooq, Shakeel Ahmad Mian

This study highlighted referral rate for X-rays with positive findings in an Emergency department of a tertiary care hospital in Makkah, Saudi Arabia. This was a retrospective review of Emergency department(ED) cards/files of patients visited (ED) of Alnoor Specialist Hospital, Makkah, Saudi Arabia, during the month of April, 2006G. The total of 660 (22\%) out of 2980 ED patients were included in the study and 1472 X-rays of different regions were done for them. Majority 288 (43.3\%) were below 24yrs of age while males 372 (56.3\%) and Saudis 400 (60\%) were predominant. The discharged patients were $572(86.6 \%)$, and $4(0.6 \%)$ were died. Six hundred and twenty $(93.9 \%)$ patients got exposures rang of 1-4 while only four $(0.6 \%)$ got more than eight exposures to X-rays. It was found that lower limb was exposed 384 times (26\%), followed by chest 320 (21.7\%). Overall 240 (16.3\%) X-rays had positive findings with majority of upper limb 60 (50\%) followed by chest 72 (22.5\%). Pelvis \& perineum had no positive Xray. Patients from injury \& poisoning were predominant 224 (33.9\%) followed by respiratory disorders 104 (15.7\%). Eighty four percent X-rays had no positive findings. Majority of X-rays were done for lower limb. Neck, pelvis \& perineum $X$-rays had no positive findings.

Saratov Journal of Medical Scientific Research 2010; 6: 612-614.

URL: http://ssmj.ru/en/2010/3/612

Increased serum homocysteine levels and glutathione-Stransferase activities in alcoholic patients attending de-addiction centre

S.R. Kulkarni, K.P. Ravindra, C. Dhume, P.V. Rataboli, E. Rodrigues, E.E. Rodrigues

The purpose of this study was to investigate the effect of heavy alcohol consumption on serum Malondialdehyde, homocysteine status and glutathione-S -transferase (GST) activities in alcoholics consuming illicit liquor from lower socioeconomic background attending deaddiction centre. The study was conducted in ninety alcoholic patients consuming illicit liquor from lower socio-economic background attending de-addiction centre and compared to healthy non alcoholic controls $(n=90)$. Serum Malondialdehyde (MDA), serum homocysteine and activities of antioxidant enzyme glutathione-S - transferase (GST) were estimated. Alcoholics consuming illicit liquor attending de-addiction centre displayed significantly higher values of serum MDA concentration, serum homocysteine levels and serum GST activities as compared to their non alcoholic healthy controls belonging to the same socio-economic background. Our results indicate that increase in serum Malondialdehyde (MDA) concentration marker of oxidative stress, serum homocysteine levels and serum glutathione-S-transferase (GST) activities may enhance the susceptibility to vascular diseases in heavy illicit drinkers with poor nutritional status.

Saratov Journal of Medical Scientific Research 2010; 6: 620-624. URL: http://ssmj.ru/en/2010/3/620

SEM evaluation of the morphological changes in hard dental tissues prepared by Er: YAG laser and rotary instruments

Georgi Tomov

Effective ablation of dental hard tissues by means of the erbium:yttriumaluminum garnet (Er: YAG) laser has been reported recently, and its application to caries removal and cavity preparation has been expected. However, few studies have investigated the morphological changes in hard dental tissues after Er: YAG laser caries treatment. In the present study the morphological changes in hard dental tissues after Er: YAG laser caries ablation in vitro was compared with that of conventional mechanical treatment. Thirty extracted human teeth with caries were used. Ten tooth was treated with the Er: YAG laser, and the other was treated with a conventional steel and diamond burs. Laser treatment was performed by means of a non-contact irradiation modes with cooling water spray, with a new Er: YAG laser (LiteTouch). Conventional bur treatment was conducted by means of a low-speed micromotor and air turbine with water cooling. Scanning electron microscope (SEM) observations were performed for each treatment. The Er: YAG laser ablated carious dentin effectively with minimal thermal damage to the surrounding intact dentin, and removed infected and softened carious dentin to the same degree as the burtreatment. In addition, a lower degree of vibration was noted with the Er: YAG laser treatment. The SEM examination revealed characteristic micro-irregularities of the lased dentin and enamel surfaces with potential benefits for adhesive restorations. Our results show that the Er: YAG laser is promising as a new technical modality for caries treatment.

Saratov Journal of Medical Scientific Research 2010; 6: 667-671. URL: http://ssmj.ru/en/2010/3/667

Twin birth order, birthweight and birthweight discordance: any relationship

Alphonsus N. Onyiriuka

Background: It is widely believed that in twin pairs, at birth, the first-born weigh more than the second-born but this concept has been challenged. Objective: To assess the truthfulness of this common concept that firstborn twins are usually heavier than their second-born siblings at birth. Methods: In a series of 104 sets of live-born twins, the birth weights of first-born twins were compared with those of their second-born siblings, after controlling for gender. Their intra-pair birthweight differences were determined and twin pairs whose birthweight difference was $15 \%$ or more were designated as discordant. Results: Twin I was heavier than Twin II in $61.5 \%$ of cases while Twin II was heavier than Twin I in $28.9 \%$ of cases. Twins I and II had equal birthweights in $9.6 \%$ of cases. Comparing the mean birthweight of the first-born-male twin with that of second-born- male twin, it was $2515+427 \mathrm{~g}$ (95\% Confidence Interval, $\mathrm{Cl}=2402-2628$ ) versus 
$2432+435 \mathrm{~g}(95 \% \mathrm{Cl}=2321-2543) \mathrm{p}>0.05$. The mean birthweight of firstborn-female twin was $2326+445 \mathrm{~g}(95 \% \mathrm{Cl}=2214-2439)$ while that of the second-born-female twin was $2325+501 \mathrm{~g}(95 \% \mathrm{Cl}=2197-2453) \mathrm{p}>0.05$. When the birthweight difference exceeded $750 \mathrm{~g}$, the probability that Twin I will be heavier than Twin II was $83.3 \%$ (5 of 6). Conclusion: Although the first-born twin was more often heavier than their second-born siblings, either could weigh more or less at birth. The larger the birthweight difference between growth-discordant twin pair, the greater the probability that the heavier twin would be delivered first.

Saratov Journal of Medical Scientific Research 2010; 6: 807-811.

URL: http://ssmj.ru/en/2010/4/807

The interaction of public-school teachers with student users of psychoactive substances

L.C. De Castro Rossi, I. Dalben, S.C. Mangini Bocchi

The increasing and early use of psychoactive substances by children and adolescents represents a challenge to public-health practice. To understand teachers' interactions with student users of drugs and develop a representative theoretical model of such experience this study was conducted. Qualitative study conducted in Sro Paulo, Brazil, with 32 teachers from public schools by means of focal groups and based on the Grounded Theory as its methodological framework. Progressively comprehensive categories converged to three phenomena: Identifying student's users; Feeling powerless in face the challenges of drugs use; Silencing to preserve oneself from a threatening scenario. These phenomena constructed the core category of the experience: Silencing to preserve oneself from a threatening scenario in face of the fragility of rescuing student's users of drugs. The clash between inducing and protective factors in the concrete situations of drugs use was revealed, thus pointing out that the lack of State and social support associated with the user's relation with drug trafficking and violence leads teachers to silence as they feel unprotected in face of a situation surrounded by stigma and prejudice. Coping strategies should include the educators, relatives, health care professionals and government institutions, thus providing ways to prevent and treat use, orientate and reconstruct lives in a process of active participation for all students.

Saratov Journal of Medical Scientific Research 2010; 6: 857-862.

URL: http://ssmj.ru/en/2010/4/857

\section{Alternative practices of health maintenance in elderly age}

Elena V. Chernyshkova

The analysis of elderly people attitude to alternative practices of health maintenance in the context of activity prolongation is presented. By the example of conducted sociological research it is demonstrated that besides medication, health resources maintenance includes the following relevant methods: physical exercises and fitness; quit pernicious habits; rational nutrition; sexual activity.

Saratov Journal of Medical Scientific Research 2011; 7: 923-925.

URL: http://ssmj.ru/en/2011/4/923 